\title{
OBITUARY
}

\section{CLARENCEDAN JOHNSON}

(1931-2005)

Dr. Clarence Dan Johnson of Flagstaff, Arizona died of acute leukemia on March 28, 2005 at age 74. He was born July 20, 1931 in Exeter, California and received his primary schooling in Tulare, California. He received his MS degree from Arizona State University, Tempe in 1961, and his $\mathrm{PhD}$ in Entomology from University of California, Berkeley in 1966. After serving in the U.S. Army from 1954 to 1956, he taught science in Fresno, California, schools 1956-1963.

In 1966, he joined the faculty of Northern Arizona University at Flagstaff as assistant professor, became an associate professor in 1970 and served as a full professor from 1976 until his retirement in 1994. He was a world authority on the classification of the beetle family Bruchidae, especially in their associations with host plants. Most of his students chose as their thesis subjects some aspect of bruchid taxonomy or their life history, and many of his more than 175 papers were in collaboration with students, or with colleagues. His numerous collecting trips in western United States, Mexico, Central America and northern South America provided study material for him and his students, and his colleagues. He was still publishing papers in 2005. His extensive collection of Bruchidae is now deposited in the arthropod collection of Texas A \& M University, College Station.

Dr. Johnson was a member of the Coleopterists Society, Sigma Xi, Pacific Coast Entomological Society, the Kansas Entomological Society, the Society of Systematic Zoology, Society for the Study of Evolution, the Ecological Society of America, the Society for Tropical Biology, the Arizona-Nevada Academy of Science and member of the International Advisory Board of the Revista Brasileira de Entomologia. He was a

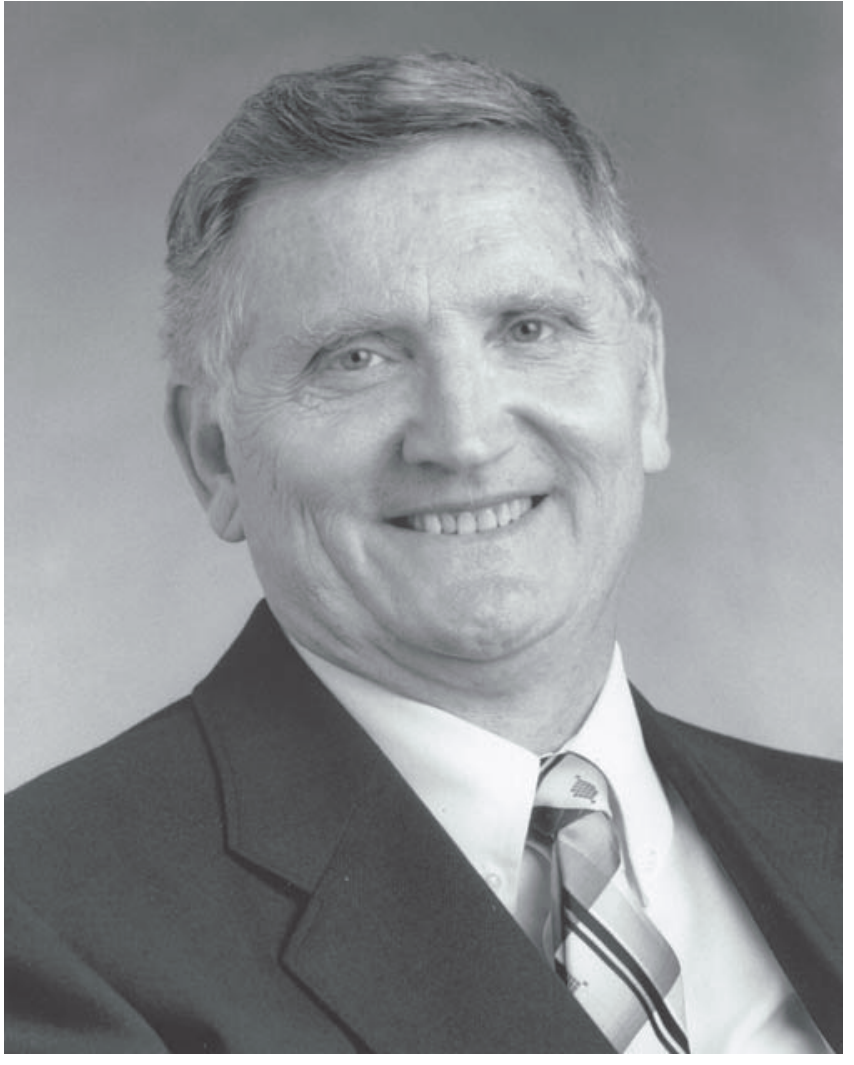

recipient of several academic awards and research grants, and participated in a number of international symposia and conferences on Bruchidae. In his position at Northern Arizona University, he was a member of numerous faculty committees as well as committees in national and international societies.

He leaves behind his wife Margaret and four children and their families.
John M. Kingsolver Cibele S. Ribeiro-Costa 